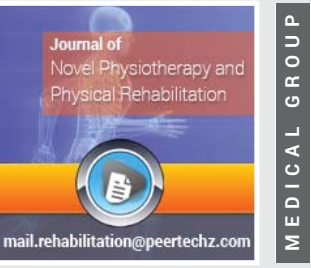

\section{Laura LoVasco*}

Assistant Professor, Department of Physical Therapist Assistant Program, South University-Novi Campus, USA

Received: 24 October, 2018

Accepted: 08 July, 2019

Published: 09 July, 2019

*Corresponding author: Laura LoVasco, PT, DScPT, DPT, Board Geriatric Specialist, Assistant Professor, Department of Physical Therapist Assistant Program, South University-Novi Campus, USA, Tel: 1-810-9229409; Fax: 1-810-750-1350;

E-mail: lovascol@aol.com;

llovasco@southuniversity.edu

Keywords: Leadership; Leadership practices inventory; DPT; Curriculum

https://www.peertechz.com

Check for updates

\section{Case Report}

\section{A Leadership Development Program for student physical therapists and therapist assistants}

\section{Summary}

Introduction: Leadership is a key characteristic needed for physical therapists and physical therapist assistants to deliver primary care in the healthcare environment. There is a need for increasing leaders in the physical therapy profession, however, there is no published research to assist with initiating leadership at the student level.

Results and discussion: Two student physical therapists (SPTs) and one student physical therapist assistant (SPTA) completed a 7-month leadership development program (LDP). The LDP merged the Leadership Challenge with the American Physical Therapy Association core values and philosophies. Students were exposed to transformational leadership, leadership practices, and used an experiential activity to practice their leadership. A combined pre/post-survey was performed at the completion of the LDP. All three participants found value in the information learned from the LDP. Leadership awareness and behaviors all increased based on the results of the combined pre/post survey. A structured LDP can be created assisting in awareness of leadership practices in students enrolled in entry-level physical therapy education programs. SPT/SPTAs can learn that all practitioners in the physical therapy field can enhance the role of the physical therapy profession in the healthcare environment. A structured LDP may assist in the ability of more SPTs and SPTAs to become leaders by linking the transformational leadership theory to their future role as practicing clinicians in the healthcare environment.

\section{Introduction}

Leadership in the physical therapy profession has been identified as a characteristic needed for primary care delivery in the healthcare environment [1-5]. The American Physical Therapy Association (APTA) Leadership Development Committee defined four core competencies for physical therapists (PTs) and physical therapist assistants (PTAs) who wish to develop their leadership skills [1]. The APTA promotes leadership development in the core competencies by providing recommended on-line resources for developing leadership skills and leadership development opportunities [6]. Two formal leadership programs available within the APTA sections are the Education Leadership Institute (ELI) Fellowship [2] and the Leadership Administration Management Professionalism (LAMP) Leadership Development Certificate Program [3].

The Commission on Accreditation in Physical Therapy Education (CAPTE) has one standard for both Doctor of Physical Therapy (DPT)/Physical Therapist Assistant (PTA) academic programs that requires only exposure to leadership through participation in professional and community organizations that provide opportunities for leadership [4]. Students in the
DPT/PTA programs are encouraged to participate as class officers, serve in pro bono clinic committees, or conduct service learning. State chapters of the APTA and the APTA Student Assembly provide leadership exposure as students are recruited through a voluntary basis to serve the profession on student committees or in student leadership positions. It is then hoped the student develops leadership through exposure and experience by self-learning along with trial and error. The importance of educating SPTs as leaders became a current focus in the Excellence in PT Education for the $21^{\text {st }}$ Century research project [5]. Leadership and vision were identified as two essential components of professional education to prepare students for their future as clinicians in formal leadership roles.

No published leadership development program exists for SPTs and SPTAs. This author merged the Leadership Challenge [7], program with the use of core and foundational information from the physical therapy profession creating a SPT/SPTA leadership development program (LDP). The purpose of this case report is twofold - 1) to outline a structured LDP that includes both transformational leadership theory and physical therapy profession philosophies to develop leadership practices 
in SPTs and PTAs and; 2) to discuss the self-reported increase in leadership awareness and behaviors of SPTs and SPTAs after using the developed LDP.

\section{Results and Discussion}

\section{Participants}

Approximately 20 SPTs and SPTAs who participated in an APTA chapter special interest group for students were recruited from a sample of convenience for the LDP. The students in the special interest group were affiliated with an entrylevel program for either a DPT or an associate PTA education program. The students were special interest group board officers, student conclave planning chairs, or DPT/PTA school representatives. No other recruitment of SPTs or SPTAs was used.

\section{Method}

The LDP was verbally described and reviewed during a SPT/ SPTA special interest group meeting. Each student was given the choice to voluntarily participate in the program and commit as a participant that day or within one month when the LDP would begin. The author created a consent form that included a short description of the Leadership Challenge leadership practices, the LDP with estimated time for activities, a contract to abide for deadline dates of assignments, and a consent to participate giving permission to use them as a participant in a case study report. The participants were informed they could discontinue at any time and would receive a certificate for entire completion at the end of the LDP.

A total of ten students agreed to participate in the LDP. There were five SPTs and five SPTAs from various DPT and PTA education programs in the state. Two participants dropped out prior to completing the first assignment and five others dropped out during the duration of the LDP. The reason all participants gave for dropping out of the program was time commitment to their DPT/PTA studies versus completing the LDP. A total of three participants, two SPTs and one SPTA, completed the entire LDP. The three participants took a combined pre-/postsurvey at the completion of the LDP.

\section{The leadership challenge}

The exploration and investigation of the best transformational leadership practices resulted in the Leadership Challenge [7]. The Leadership Challenge describes how the best leaders engage in five practices of exemplary leadership (Table 1).

The self-awareness of the individual's personal leadership practices' strength is combined with information provided in the Leadership Challenge as a means to assist with improvement of selected leadership practices. The Leadership Challenge has been used for multiple industries, including health care.

The Leadership Challenge was chosen because this author believes the five key practices of exemplary leaders have similar descriptions and values as the APTA Core Values of Professionalism [8] (Table 2).
Table 1: The Five Practices of Exemplary Leadership [3]

Model the Way

Leading by good example and living what you say. Giving clear guiding principles and clarify values and setting examples through daily actions that demonstrate deep commitment to the beliefs.

Inspire a Shared Vision

Envisioning exciting and ennobling possibilities, enlist others to the common vision by sharing it, talking about it, getting exciting about it, and making decisions to make it happen.

\section{Challenge the Process}

Step out into the unknown and search for opportunities to innovate, grow, and improve. Means taking risks and believing that taking them is thought out and worthwhile. Use experimenting and taking risks while making the team feel safe. Learn from failures.

Enable Others to Act

Using the word "we", include everyone who have a stake in the vision. Strengthen everyone's capacity to deliver for the team.

Encourage the Heart

Genuine acts of caring to uplift the spirits and draw people forward together, recognize contributions both one on one and with many people, celebrate values and victories.

The philosophy of the Leadership Challenge is that is not prescriptive, but includes principles that shape selfdevelopment. Some examples of the principles are leadership is everyone's business and leadership should be treated like a relationship [7]. Leadership is an aspiration and a choice that includes learning and practice; ultimately making a difference in work setting cultures [7]. The Leadership Challenge is a very simple program to follow with five leadership practices and two commitments for each practice. The program has withstood time; developed over twenty-five years ago with consistency to the content related to the qualitative collection of peak leadership experiences [7].

\section{Leadership development program}

The LDP was created by the author and modeled using the Leadership Challenge [7], with specific physical therapy professional examples that included the APTA strategic plan [8], APTA vision [10], ethics [11], core values [8] and standards of practice [12]. No validity or reliability has been determined since this is the first time using the LDP. The LDP spanned over a seven-month period with communication via email between the author and the participants. The LDP was provided in three phases - Phase One: Overview of leadership; Phase Two: Transformational leadership and introduction of the five leadership practices; and Phase Three: Experiential learning using the five leadership practices.

The first two phases of the LDP consisted of information provided about leadership in general, more specifically about the transformational leadership theory $[13,14]$ and the leadership practices [7]. The participants were asked to read the preface and chapters of the Leadership Challenge. Reflection activities with posed questions were used have the participants compare their thoughts between the overview information, readings, and the physical therapy profession. Discussions related to the profession's strategic plan and how to implement a project related to the strategic plan were included in this phase. The first two phases took three month to complete with one month off due to timing of the end of a semester and holidays. 
Table 2: Comparison of Leadership Practices ${ }^{7}$ and APTA Core Values (APTA Core Values).

\begin{tabular}{|c|c|c|}
\hline $\begin{array}{l}\text { Posner/ } \\
\text { Kouzes Key } \\
\text { Leadership } \\
\text { Practices }\end{array}$ & $\begin{array}{l}\text { APTA Core } \\
\text { Values Related } \\
\text { to Leadership } \\
\text { Behaviors }\end{array}$ & $\begin{array}{l}\text { APTA Core Values } \\
\text { Definition }\end{array}$ \\
\hline $\begin{array}{l}\text { Model the } \\
\text { Way }\end{array}$ & Accountability & $\begin{array}{l}\text { Accountability: Active acceptance of the } \\
\text { responsibility for the diverse roles, obligations, } \\
\text { and actions of the physical therapist including } \\
\text { self-regulation and other behaviors that positively } \\
\text { influence patient outcomes, the profession and } \\
\text { the health needs of society. } \\
\text { Integrity: Steadfast adherence to high ethical } \\
\text { principles or professional standards; truthfulness, } \\
\text { fairness, doing what you say you will do, and } \\
\text { "speaking forth" about why you do what you do. }\end{array}$ \\
\hline $\begin{array}{l}\text { nspire Shared } \\
\text { Leadership }\end{array}$ & $\begin{array}{c}\text { Social } \\
\text { Responsibility }\end{array}$ & $\begin{array}{c}\text { Social responsibility: Promotion of a mutual trust } \\
\text { between the profession and the larger public that } \\
\text { necessitates responding to societal needs for } \\
\text { health and wellness. } \\
\text { Professional duty: Commitment to meeting } \\
\text { one's obligations to provide effective physical } \\
\text { therapy services to patients/clients, to serve the } \\
\text { profession, and to positively influence the health } \\
\text { of society. }\end{array}$ \\
\hline $\begin{array}{c}\text { Challenge the } \\
\text { Process }\end{array}$ & Excellence & $\begin{array}{l}\text { Excellence: Practice that consistently } \\
\text { uses current knowledge and theory while } \\
\text { understanding personal limits, integrates } \\
\text { judgment and the patient perspective, embraces } \\
\text { advancement, challenges mediocrity, and works } \\
\text { toward development of new knowledge. }\end{array}$ \\
\hline $\begin{array}{c}\text { Enable Others } \\
\text { to Act }\end{array}$ & Altruism & $\begin{array}{l}\text { Altruism: Regard for or devotion to the interest } \\
\text { of patients, thus assuming the fiduciary } \\
\text { responsibility of placing the needs of the patient } \\
\text { ahead of the physical therapist's self-interest. }\end{array}$ \\
\hline $\begin{array}{c}\text { Encourage the } \\
\text { Heart }\end{array}$ & Compassion & $\begin{array}{l}\text { Compassion: Desire to identify with or sense } \\
\text { something of another's understanding the socio- } \\
\text { cultural, economic, and psychological influences } \\
\text { on the individual's life in their environment. } \\
\text { Caring: Concern, empathy, and consideration for } \\
\text { the needs and values of others. }\end{array}$ \\
\hline
\end{tabular}

Phase Three consisted of two parts - continued readings and reflections on the leadership practices and an experiential activity. Using the activity chosen during the end of Phase Two, the participants were asked to implement the activity over a three month time period. Each participant was instructed to obtain three or more people to participate in the activity. The participants used, practiced, and reflected on their personal leadership practices while performing their group activity. Assignments included participants' journal reflections stimulated by questions posed by the author. The author then provided written feedback throughout the reflection that included confirmation, disagreement, praise, or query to assist with the participants' leadership development. The author developed a combined pre-/post-survey that was not included in the LDP. The survey included permission to use the participants' survey information in a confidential manner for the case study. All three participants took the survey and gave consent.

\section{Outcomes}

The survey was an afterthought on the part of the author, so a combination pre-/post-survey was offered and completed by the three participants. Twenty questions were posed with a 1 - 5 Likert scale intensity of agree/disagree (1=strongly disagree, $3=$ =neutral, $5=$ strongly agree) for each of the statements. Statements of leadership behaviors related to the five leadership practices of the Leadership Challenge were developed with the assistance from the Leadership Challenge Workshop Participant Workbook, $4^{\text {th }}$ ed [15]. The survey included a comment section for each question.

The increased changes in scores from the pre- to the post-survey showed there may have been an actualization of leadership development occurring in the three participants in the study (Table 3), though no formal statistics were used on the pre and post data due to the low number of participants.

The average pre-LDP data for expressing the definition of transformational leadership was 2.0, whereas, the post-average was 4.0. A comment from one student was "I think the program helped me form an idea or personal definition of what being a leader means." Self-assessment of leadership strengths using the leadership practices averaged 2.0 pre-survey and 5.0 postsurvey with the comment "Kouzes and Posner information helped me be more specific in my self-assessment." Ratings of personal leadership went from an average of 2.3 pre-survey to a 4.0 post-survey with participants' comments of "I know what all the different types of leaders are and I am able to recognize my style" and "Before the program I wouldn't really think of myself of a leader, doing the assignments has helped me realize that I can be a leader and am a good leader when I put my mind to it and try."

Survey questions that focused on the specific leadership behaviors resulted with questions averaging pre-survey of 3.3 with an increased average rating to 4.5 post-survey (Table 4).

Overall comments from the participants about the LDP were "the program was helpful because of the structure of the program with readings, reflections, and activities; the timeline was manageable to complete with other responsibilities such as school, work, research, etc.; and "I loved doing the last assignment because it really motivated me to make a change". General comments from the participants related to improvement of the LDP were "more interaction with other members taking the course including recommendations for group reflection sessions over the phone or in person".

\section{Discussion}

A structured LDP that merges both transformational leadership theory and physical therapy profession philosophies can be created to assist in developing leadership practices in SPTs and SPTAs. The structured LDP used in this study demonstrated increases in two SPTs' and one SPTA's leadership awareness and practices based on the three participants' pre- and post-survey scores. Comments from the students that highlight the importance of connecting leadership to the profession were related to increased awareness of the APTA strategic plan and core values of the profession (Table 4). 
Leadership development is a personal choice of the individual. Persons who seek out leadership development skills may be those who believe they have good baseline leadership characteristics, have had experience in a leadership position, or may have been encouraged to seek out leadership positions. The process of leadership development is a journey that includes personal understanding of transformational leadership and growth of leadership practices [7]. It is this author's belief that limited exposure of leadership theory or an endorsed leadership role with no mentoring or connection of leadership theory to the profession cannot assist in producing a substantial number of leaders in the physical therapy profession. Students who are most interested in a leadership position or have developed leadership skills from previous experiences prior to the DPT or PTA educational experience may be the students who tend to gravitate toward encouraged leadership positions provided in DPT/PTA education programs. There may be some students who need assistance with recognizing their leadership abilities, be given direction, and fine tune their leadership capabilities. There are also students who have no desire to participate in leadership activities, however, need to have a good understanding of leadership practices. The student who is not interested in a leadership position can be shown that all physical therapists or physical therapist assistants can practice leadership and have an impact on patient care, interprofessional relationships, and elevate the physical therapy profession role in a healthcare environment.

The several resources of the APTA focus on the practicing clinician and not the student for leadership development. The ELI program was developed for those in the academic setting and the LAMP program primarily focuses on the licensed

Table 3: Pre-Survey and Post-Survey Averaged Results Related to General Questions About Leadership.

\begin{tabular}{|c|c|c|}
\hline Question & Pre & Post
\end{tabular}

I can express the definition of transformational leadership to another person

Comment: I think the (leadership) program helped me form an

idea or personal definition of what being a leader means.

I can self-assess my leadership strengths using the Posner/

Kouzes leadership practices

Comment: I could self-assess before the (leadership) program,

but I think the Posner/Kouzes (leadership practices) helps me be

more specific in my self-assessment.

I would rate myself as a leader

Comments: I now know what all the different types of leaders

are, and I can recognize my style.

Before the (leadership) program I wouldn't really think of myself

of a leader, doing the assignments has helped me realize that I

can be a leader and am a good leader when I put my mind to it

and try.

Apply the lessons learned during the Leadership Development

Program to current challenges to the PT profession

Comment: I used my knowledge gained with the program to help

me with presentations in my clinicals.

Changed as a leader in the PT community

Comments: This program has really helped to improve my

confidence and I am grateful for it.

I felt the program helped me become a better leader, it helped me find my own voice in leading.
Table 4: Pre-Survey and Post-Survey Averaged Results Related to Leadership Practices.

Question

I model the Core Values of the APTA

I can state the vision of APTA

Comment: Not that I couldn't state the vision before, but I didn't really $2.7 \quad 4.3$ look it up until I was in the (leadership) program

I can lead a group of people confidently by using the Posner/Kouzes Leadership Practices

Comment: I was leading small groups of people in exercise at my job before the program, but I was able to lead larger groups more effectively after the program

I can clarify and communicate my fundamental values and beliefs of the PT profession

Comments: I have had an increase in the quantity and quality of the conversations I have had about the profession.

We did learn the core values before the program, but I feel more confident with my ability to communicate the values better after the program.

I can set the example for others by aligning my actions with shared values of the physical therapy profession

Comment: While I did align my actions with the values of physical therapy before I feel after doing the different assignments have helped me be better able to show to others my values.

I can express my image of the future for the physical therapy profession

Comment: I think the program has helped me change and be better at $\quad 3.7 \quad 4.3$ expressing my image of where the physical therapy profession should be in the future

I can inspire others to share a common vision, such as the vision of the PT profession

I search for opportunities to change and improve the PT profession Comment: I am now more aware of what the PT profession is trying to accomplish and actively try to do my part to aid in accomplishing the common goals we have.

I build collaboration, teamwork, and trust

I experiment with innovative ideas and learn from accompanying mistakes

I strengthen the ability of others to excel

I recognize the accomplishments of others

clinician [2,3]. The CAPTE standard [4], is very limited in definition of leadership or the use of leadership theory. CAPTE is not intended to be prescriptive for the content in DPT/ PTA education programs, however, could assist with SPT and SPTA leadership development by enhancing the standard to include the student partake in leadership roles. The Excellence in PT Education for the $21^{\text {st }}$ Century research project connects the profession to leadership through the acknowledgment of enhancing leadership development at the student level to assist in meeting the needs of the APTA Strategic Plan. The LDP used in this case study focused on transformational leadership, whereas, the Excellence in PT Education for the $21^{\text {st }}$ Century research project focused on shared leadership [5]. Both leadership theories are very similar with the leader developing team members, using team members' strengths, and creating a productive team approach culture $[13,14]$.

The LDP allowed students to develop appropriate awareness and skill in leadership practices using a simplified structure, guidance from an experienced physical therapist and Leadership 
Challenge facilitator, and time to actualize leadership practices that had meaning to the student and to the physical therapy profession. The LDP was seven months in duration showing that the development of leadership skills of students can be done in the duration of time in the entry-level DPT and PTA education programs. The LDP described was based from a current, usable leadership theory and a process that has been researched, developed, and published [7]. There are continuing education courses for the Leadership Challenge that could be used for SPTs and SPTAs to participate in and courses to become a facilitator of the program for physical therapy faculty to teach in their respective DPT/PTA education programs.

The LDP was developed to focus on the physical therapy profession allowing students to discover the importance of the profession's strategic goals and values. The use of the participant choosing an APTA strategic goal [9], added meaning for the material taught in most early entry-level DPT/PTA professionalism courses. The LDP allowed the participants to realize that transformational leadership is more than a status or hierarchal position. The participants were able to understand that their role of a transformational leader is to keep the team focused on the goal, to develop team members who require assistance, strategically use team members' strengths, and to praise all team members for the effort to achieve the goal [713].

\section{Limitations}

The participants in this study were from a sample of convenience recruited from a group that were engaged in leadership roles. The interest in leadership may have been the factor for the awareness and improvement in the understanding of leadership practices. The LDP was not offered to students who may have been hesitant or disinterested in a leadership role. The combined pre-/post-survey was an afterthought of the author, thus the participants' results on the pre-scores may not have been accurate since they were rated after the completion of the LDP. The answers to the survey questions were self-perceptions of the participants. The survey was not taken through an appropriate process for the best face validity, however, the questions were developed with assistance from a trusted source [15]. Future studies should include testing the validity and reliability of the LDP by using the Self Leadership Practices Inventory [16], for pre and post self-assessment of leadership practices.

\section{Conclusion}

While there is a clear need for leaders in the physical therapy profession, there is not concise leadership development content in DPT/PTA education programs. A transformational leadership development program such as the Leadership Challenge can be used to merge with the physical therapy professional values and vision into an LDP for DPT/PTA education programs. The use of a more structured LDP may assist in the ability of more SPTs and SPTAs to link the transformational leadership theory to their future role as practicing clinicians in the healthcare environment.

\section{References}

1. (2017) Leadership Development. American Physical Therapy Association Link: http://bit.ly/2L8R4s 1

2. (2017) Education Leadership Institute (ELI) Fellowship. American Physical Therapy Association Link: http://bit.ly/2Xtsysi

3. (2017) Health Administration and Policy Section: Leadership Development Programs and Events, LAMP Leadership Development Certificate Program, American Physical Therapy Association. Link: http://bit.ly/2XvqcV7

4. (2018) Information for Program Directors and Faculty at Accredited Programs. Commission on Accreditation in Physical Therapy Education. Link: http://bit.ly/2S1EYlc

5. Jensen GM, Hack LM, Nordstrom T, Gwyer JL, Mostrom E (2017) National Study of Excellence and Innovation in Physical Therapist Education: Part 2: A Call to Reform, PTJ 97: 875-895. Link: http://bit.ly/2LKAONt

6. (2016) Recommended Resources for Developing Leadership Skills. Link: Link: http://bit.ly/2L8R4s1

7. Kouzes JM, Posner BZ (2013) The Leadership Challenge. 5th Ed.", Jossey Bass, San Francisco, CA. Link: http://bit.ly/2xGT2ah

8. (2017) Professionalism in Physical Therapy: Core Values, BOD P05-04 (Amended BOD 08-03-04-10, APTA website, 2010). American Physical Therapy Association. Link: http://bit.ly/2JsHQ6R

9. (2014) Strategic Plan. American Physical Therapy Association. Link: http://bit.ly/30oEuJ4

10. (2013) Vision Statement for the Physical Therapy Profession, HOD P06-1318-American Physical Therapy Association. Link: http://bit.ly/2xy7cdN

11. (2017) Code of Ethics for the Physical Therapist. American Physical Therapy Association. Link: http://bit.ly/2L8UsmZ

12. (2017) Standards of Practice for Physical Therapy, HOD S06-12-15. American Physical Therapy Association. Link: http://bit.ly/2NUvnOX

13. Burns J (1978) Leadership, Harper \& Row, New York. 20. Link: http://bit.ly/2Jma4Bm

14. Pearce CL, Conger JA (2002) Shared Leadership: Reframing the Hows and Whys of Leadership CA 1. SAGE Knowledge. Link: http://bit.ly/2NHCrhA

15. Kouzes JM, Posner BZ (2013) Leadership Challenge Workshop Participant Workbook, 4th ed" (Kouzes and Posner Workbook), Pfeiffer, San Francisco, CA.

16. Kouzes JM, Posner BZ (2017) Leadership Practices Inventory (LPI-Self): Self Instrument, 3rd Ed, John Wiley and Sons. Link: http://bit.ly/2G0TXHI

Copyright: @ 2019 Lovasco L. This is an open-access article distributed under the terms of the Creative Commons Attribution License, which permits unrestricted use, distribution, and reproduction in any medium, provided the original author and source are credited. 